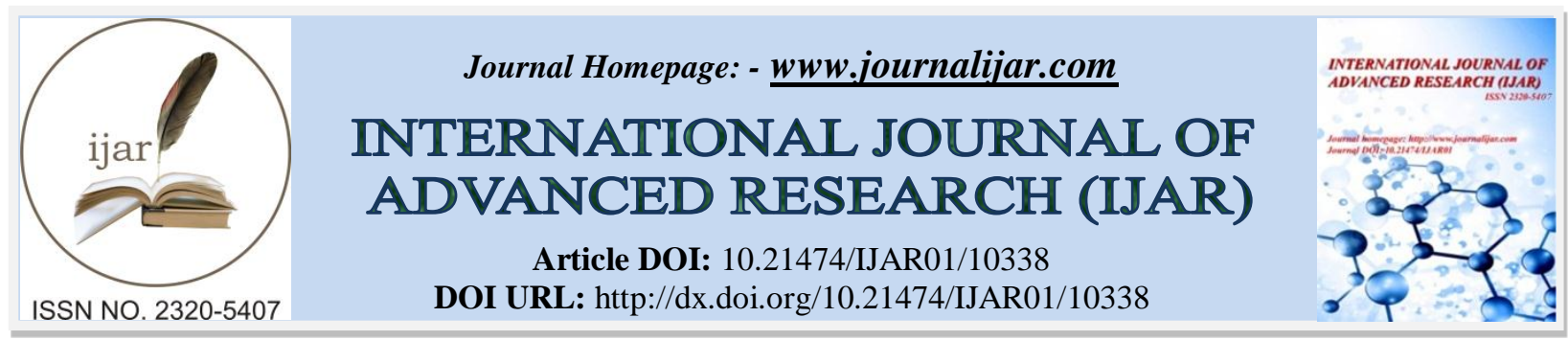

RESEARCH ARTICLE

\title{
CORRELATION BETWEEN HAEMATOCRIT LEVEL AND THE DURAL SINUS DENSITY: AN EXPERIENCE OF A SINGLE CENTER IN TAIF, SAUDI ARABIA
}

\author{
Yahea A. Alzahrani \\ Assistant Professor of Radiology, Consultant of Radiology, College of Medicine, Taif University, Saudi Arabia.
}

\section{Manuscript Info}

Manuscript History

Received: 27 November 2019

Final Accepted: 30 December 2019

Published: January 2020

Key words:-

Hematocrite\%, Hounsfield Unit, Venous

Sinus Thrombosis, Dural Sinus Density, High Altitude

\section{Abstract}

Background: The increase in the level of haematocrite results in an increase in the x-ray attenuation within the vasculature, which may lead to a considerable variability among patients in the radiodensity during performing a computerized tomography (CT) images within the intracranial vasculature.

Objectives:The current study aimed to investigate the correlation between haematocrit levels and CT density of dural sinuses.

Subjects and Methods: A single-center study was carried out on 49 subjects who admitted to the emergency department, throughout the period June-December, 2019 who underwent unenhanced head CTs. Patients were imaged using a 128-detector row CT scanner. A complete blood count (CBC) within a 24-hour period, regardless of patient symptoms or signs was performed to all subjected enrolled in the study. Results: Dural sinus density ranged between 40 and 72 Hounsfield unit (HU) with a mean of 55.9 and standard deviation of $8.2 \mathrm{HU}$. There was a significant positive correlation between dural sinus density and haematocrit values of the patients $(\mathrm{r}=0.49, \mathrm{p}=0.001)$. Also, there was a significant negative correlation between dural sinus density and patients`age $(\mathrm{r}=-0.38, \mathrm{p}=0.010)$. Dural sinus density was significantly higher among female than male patients $(58.59 \pm 8.20$ vs. $52.68 \pm 7.14$, $\mathrm{p}=0.011$ ).

Conclusion: Living in a high altitude arealeads to an increase in hematocritelevel whichmight lead to appearance of CT findings as the patient has false venous sinus thrombosis. Therefore, this should be taken into consideration.

Copy Right, IJAR, 2020,. All rights reserved.

\section{Introduction:-}

It is well known that hypoxia resulted from chronic high altitude produces an increase in hemoglobin concentration as well as red blood cell count and hematocrit values. ${ }^{1-2}$ In addition, recently Akunov et al (2018) concluded that hemoglobin levels have a linear relationship with the duration of exposure to intermittent hypoxia. ${ }^{3}$

This increase in the levels of hemoglobin or hematocrite levels result in an increase in x-ray attenuation within the vasculature $^{4}$ which may lead to variability between patients in the radiodensity on CT images within the intracranial vasculature. ${ }^{3}$ 
Limited information about the possible correlation between hematocrit level and dural density has been reported. ${ }^{5-}$

${ }^{8}$ However, recently a study included 166 aged between 2 and 100 revealed a positive correlation between hematocrit levels and CT attenuation in cerebral venous sinuses. ${ }^{3}$

The current study aimed to screen the possible correlation between the haematocrit levels and CT density of dural sinuses in Alhada, 1900 meter above sea level.

\section{Materials and Methods:- \\ Ethical approval:-}

The current study was approved from the Ethical committee of the Al-Hada hospital and a written informed consent was obtained from each subject prior to enrollment in the study.

\section{Subjects:-}

This study was included all cases admitted to emergency department, Al-Had armed Forces hospital, Taif throughout the period June-December, 2019 who underwent unenhanced head CTs (n:49). All included patients had complete blood count (CBC) test within a 24-hour period, regardless of patient symptoms or signs. Patients with intracranial artifact, pathology, trauma-related injury or postoperative changes that might influence the venous sinus density were excluded. Patients who had received contrast material for another study within 3 days of the CT or if they were suspected clinically to have a venous sinus thrombosis were also excluded. Patients who had complete blood count within 24 hours of the CT were included.

Patients were imaged using a 128-detector row CT scanner (Somatom Definition AS; Siemens Medical Solutions, Forchheim, Germany). Images were acquired by using CT parameters of $120 \mathrm{kV}$; section thickness, $5 \mathrm{~mm} ; 320 \mathrm{~mA}$; and pitch: $0.55 \mathrm{~m}$.

Axial unenhanced CT scan of the brain was reviewed by using the picture archiving and communication system by one neuroradiologist. A region of interest (ROI) was drawn by using a cursor within the inferior aspect of the superior sagittal sinus in all cases. We manually created a circular or elliptical ROI of varying volume, ranging from 5 to $9 \mathrm{~mm} 2$ making it as large as possible without overlapping with the sinus wall (Fig 1). The ROI does not include the sinus wall or artifact from the adjacent calvarium considered to be an accurate representation of reality.

\section{Statistical Analysis:-}

Data entry and statistical analysis were done using the statistical Package for Social Sciences (SPSS) software, version 25. Spearman`s correlation coefficient was used to test for the linear relationship between age, HCT and CT density of dural sinuses. Two-tailed t-test was applied to test for the difference in means of CT density of dural sinuses between male and female patients. Statistical significance was determined at $\mathrm{p} \leq 0.05$.

\section{Results:-}

1. The study included 49 patients. Their age ranged between 4 and 94 years with a mean of 46.9 and standard deviation of 25.2 years. Females represent $55 \%$ of them.

2. Dural sinus density ranged between 40 and 72 Hounsfield unit (HU) with a mean of 55.9 and standard deviation of 8.2 HU. Figure 2 shows a significant positive correlation between dural sinus density and heamatocrit $\%$ of the patients $(\mathrm{r}=0.49, \mathrm{p}=0.001)$.

3. Figure 3 demonstrates a significant negative correlation between dural sinus density and patients`age $(\mathrm{r}=-0.38$, $\mathrm{p}=0.010)$.

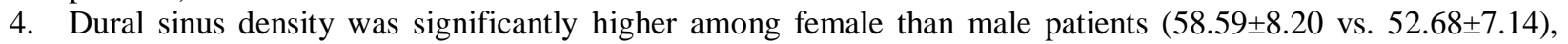
$\mathrm{p}=0.011$. Table 1

\section{Discussion:-}

The present study confirms findings of others9-11 that dural sinus radiodensity correlated positively with haematocrit level. This finding is very important, particularly in our situation of living in a high altitude area $(6,600$ $\mathrm{ft}$ above sea level) as the increase in haematocrite level might lead to appearance of CT findings as the patients have false venous sinus thrombosis. Black et al9 observed in their cohort that some patients with sinus thrombosis had $\mathrm{HU}>70$ and the highest HU without sinus thrombosis was 69. In the present study, we excluded patients with suspected venous sinus thrombosis. 
In the current study, the dural sinus density ranged between 40 and 72 Hounsfield unit (HU) with a mean of 55.9 and standard deviation of $8.2 \mathrm{HU}$. Relatively lower figures have been reported by others. In Lee et al study, 10 the mean densities ranged between 24.7 and 53.7 HU with a mean of 43.3, while Black et al9 reported a range of 32-69 HU. Among pediatric population, Osborn et al observed a range of 50 and 68 HU12 whereas among adult population, Virapongse reported a mean of 50 HU and SD of 7.5.13 The relatively higher value of dural sinus density observed in this study could be attributed to the fact that our patients were recruited from a high altitude area with relatively higher hematocrit levels.

The current study revealed that dual sinus density correlated negatively with patient's age. This coincides with what has been observed by Mahlknecht and Kaiser that haemoglobin/hematocrite levels in healthy elders are generally lower than those in younger adults.14 This is again confirms indirectly the relationship between HCT and dural sinus density.

It is documented that the level of haematocrite is higher in males than female and this variation has been suggested to be due to a genetic basis.15 However, in the present study, female patients had significantly higher dural sinus density, which we cannot explain it by variation in the hematocrite level. Further in-depth investigation is recommended to explain this unexpected finding

The study has some limitations that should be addressed. The relatively small number of cases included in it limits the precision of conclusions regarding the observed findings. Despite of that, our findings indicated that haematocrit level might be helpful clinically, further studies with higher numbers of cases are recommended. In this study, only one scanner utilized and one radiologist interpreted the findings as Hus usually vary slightly from scanner to scanner and also the interpretation could be slightly different from one radiologist to another and this would increase the precision of our findings.

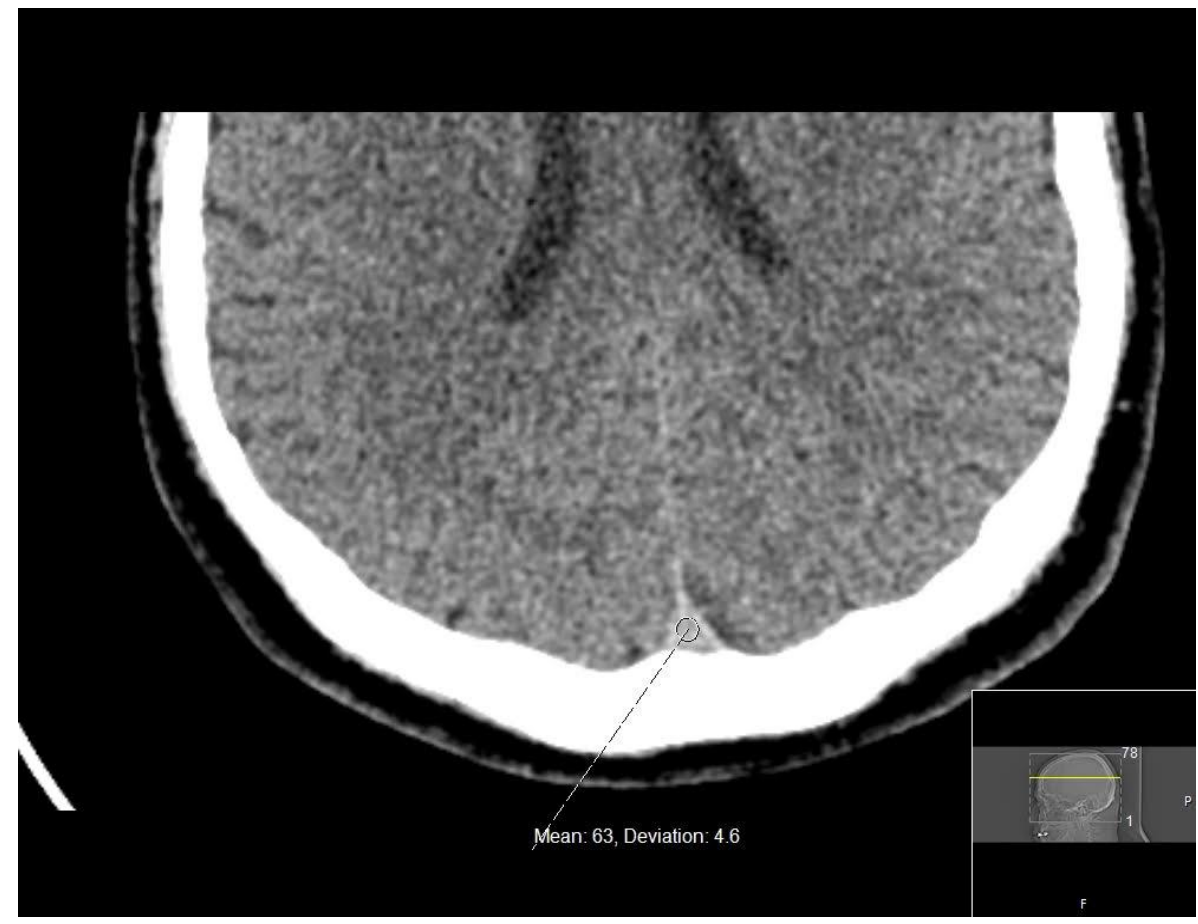

Figure 1:- Selected cute of the non-enhanced CT scan of the brain to demonstrate the placement of the region of the interset within the lower aspect of the superior sagittal sinus to measure the dural sinus density in Hounsfield unit. 


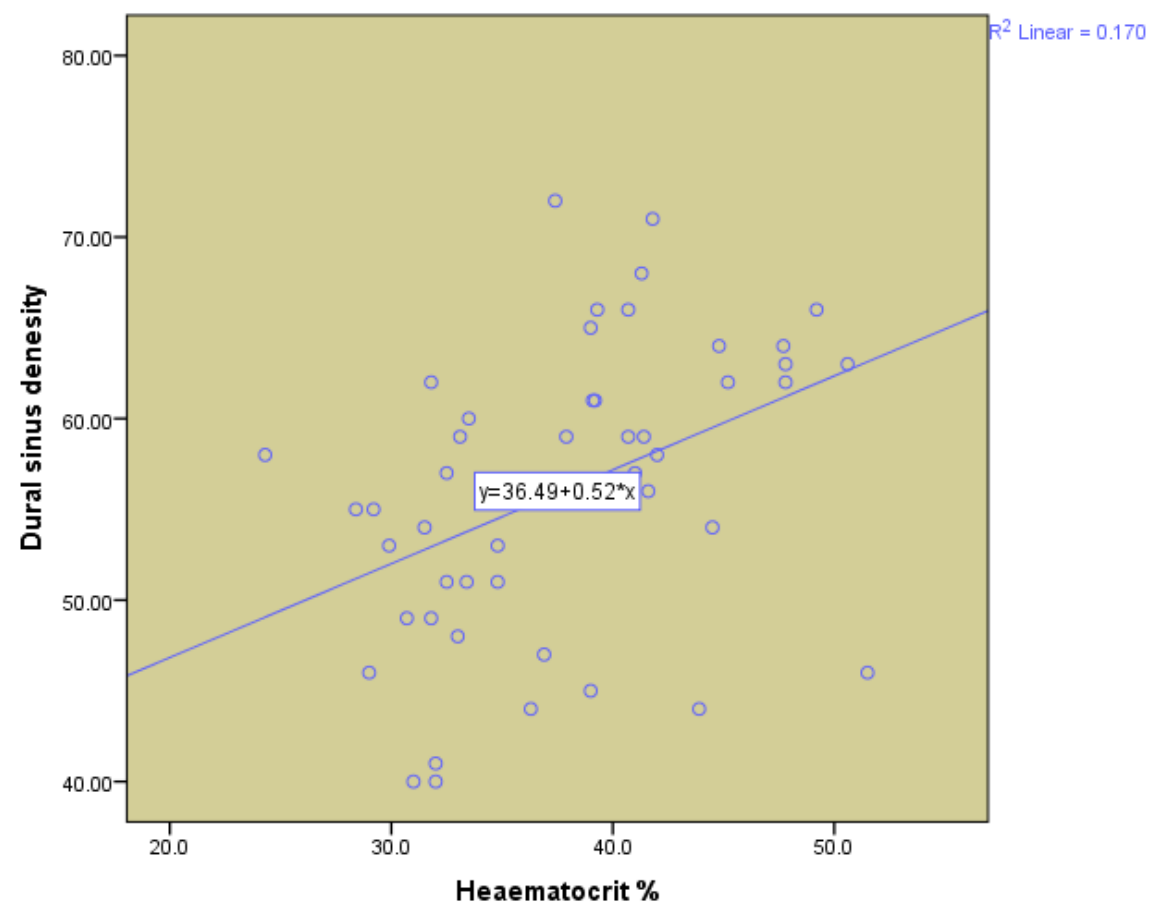

Figure 2:- Scatterplot and correlation between haematocrit $\%$ and dural sinus density.

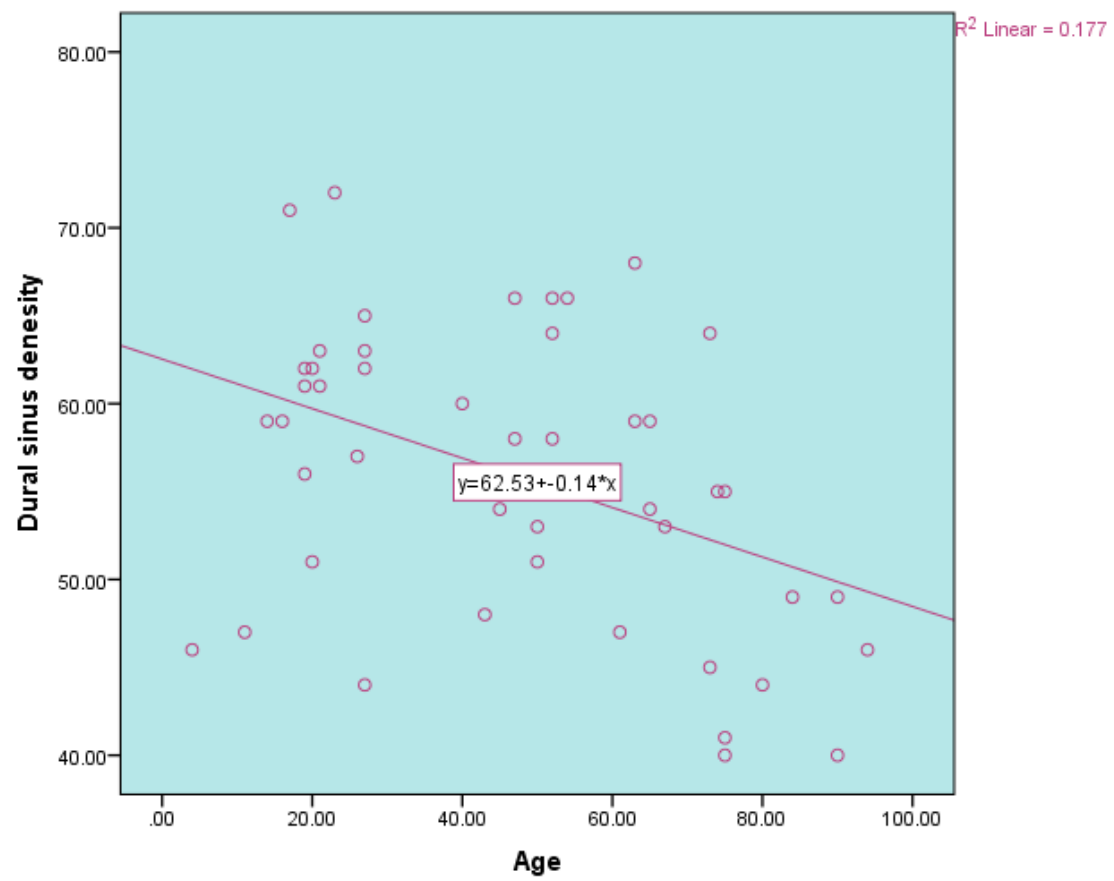

Figure 3:- Scatterplot and correlation between age and dural sinus density.

Table 1:- Comparison of dural sinus density (HU) between male and female patients ( $\mathrm{n}=49$ ).

\begin{tabular}{|l|l|}
\hline & Mean \pm SD \\
\hline Male $(\mathrm{n}=22)$ & $52.68 \pm 7.14$ \\
\hline Female $(\mathrm{n}=27)$ & $58.59 \pm 8.20$ \\
\hline
\end{tabular}

$\mathrm{P}=0.011$ 


\section{Conclusion:-}

Radiological dural sinus density correlates positively with HCT Level and negatively with patient`s age and more likely to be higher in female than male patients. Living in a high altitude area leads to an increase in haematocrite level which might lead to appearance of CT findings similar to what is detected in false venous sinus thrombosis. Moreover, correlation with haematocrit level in addition to the clinical assessment would be helpful to decide to weather the confirmatory neuroimaging studies such as CT venography are warranted to rule out dural sinus thrombosis.

\section{References:-}

1. Burtscher M, Gatterer H, Burtscher J, Mairbaurl H. Extreme terrestrial environments: life in thermal stress and hypoxia. a narrative review. Front. Physiol. 2018;9: 572. doi: 10.3389/fphys.2018.00572

2. Leon-Velarde F, Gamboa A, Chuquiza JA, Esteba WA, Rivera-Chira M, Monge CC. Hematological parameters in high altitude resident living at 4,355, 4,660, and 5,500 meters above sea level. High Alt. Med. Biol. 2000;1: 97-104. doi: 10.1089/15270290050074233

3. Akunov A, Sydykov A, Toktash T,Doolotova A,Sarybaev A. Hemoglobin Changes after long-term intermittent work at highaltitude. front. Physiol. 2018;9:1552.doi: 10.3389/fphys.2018.01552

4. Stein J, Huerta K. Ask CalJEM: when looking at a non-contrast head CT, whatactually appears white in an acute hemorrhagic stroke? Cal J Emerg Med2002;3(4):70-71

5. Collins AJ, Gillespie S, Kelly BE. Can computed tomography identify patientswith anaemia? Ulster Med J 2001;70:116-18

6. Ben Salem D, Osseby GV, Rezaizadeh-Bourdariat K, et al. Spontaneous hyperdenseintracranial vessels seen on CT scan in polycythemia cases. J Radiol2003;84:605-08

7. New PF, Aronow S. Attenuation measurements of whole blood and bloodfractions in computed tomography. Radiology 1976;121:635-40

8. Nelson MD Jr, Thompson JR, Hinshaw DB Jr, et al. Radiodensedural sinuses:new CT sign in patients at risk for hypoxemic insult. AJNR Am J Neuroradio11981;2:545-48

9. Black DF, Rad AE, Gray LA, Campeau NG, Kallmes DF. Cerebralvenous sinus density on noncontrast CT correlates with hematocrit.AJNR Am J Neuroradiol 2011;32:1354-7.

10. Lee SY, Cha SH, Lee SH, Shin DI. Evaluation of the effect of hemoglobin or hematocrit level on dural sinus density using unenhanced computed tomography. Yonsei Med J. 2013;54(1):28-33. doi:10.3349/ymj.2013.54.1.28

11. Rad AE, Gray LA, Campeau NG, Kallmes DF. Cerebralvenous sinus density on noncontrast CT correlates with hematocrit.AJNR Am J Neuroradiol 2011;32:1354-7.

12. Osborn AG, Anderson RE, Wing SD. The false falx sign. Radiology1980;134:421-5.

13. Virapongse C, Cazenave C, Quisling R, Sarwar M, Hunter S. Theempty delta sign: frequency and significance in 76 cases of duralsinus thrombosis. Radiology 1987;162:779-85.

14. Mahlknecht U, Kaiser S. Age-related changes in peripheral blood counts in humans. Experimental and Therapeutic Medicine 2010;1: 1019-1025 DOI: 10.3892/etm.2010.150

15. Zeng SM, Yankowitz J, Widness JA, Strauss RG. Etiology of differences in hematocrit between males and females: sequence-based polymorphisms in erythropoietin and its receptor. J GendSpecif Med. 2001;4(1):35-40. 